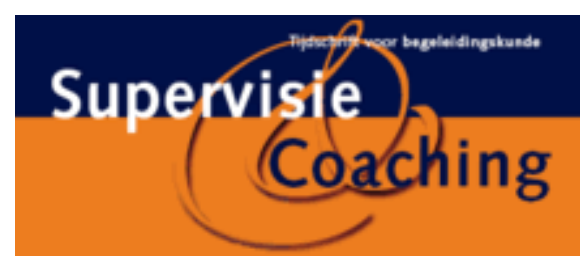

\title{
Artikel
}

\section{Onderzoek naar de effecten van supervisie}

Mieke Voogden Marijke Kuyvenhoven*

Supervisie en Coaching jaargang 27, nummer 1 (2010) p. 3-14

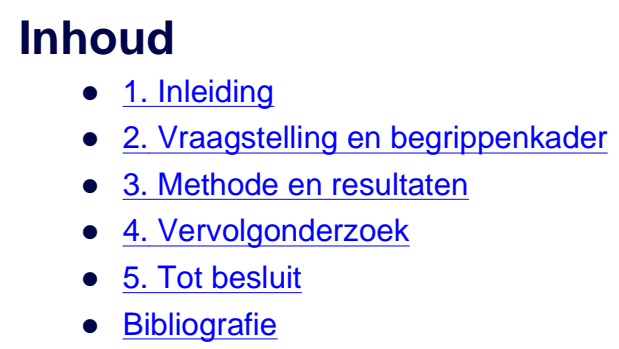

Wat is de empirische basis van ons werk als supervisor? In hoeverre is er wetenschappelijk onderzoek gedaan naar de effecten van supervisie? De auteurs van dit artikel kwamen tot deze vragen tijdens hun opleiding tot supervisor. Onafhankelijk van elkaar wijdden zij er hun afstudeerwerkstuk voor de supervisieopleiding aan (Voogd, 2008; Kuyvenhoven, 2009). In het Kennisplatform Onderzoek naar Supervisie, voorloper van de Commissie Kennis en Onderzoek van de LVSC, troffen zij elkaar en besloten hun werkstukken te integreren tot een artikel.

\section{Inleiding}

Doel van dit artikel is informeren. We willen professioneel begeleiders die nieuwsgierig zijn naar de empirische basis van de effecten van supervisie op de hoogte brengen van wat wij gevonden hebben. Dit kan een aanzet vormen voor vervolgonderzoek en verdere kennisontwikkeling op het gebied van supervisie voor dit tijdschrift. Eerst lichten we onze vraagstelling en de gehanteerde begrippen toe (par. 2). Vervolgens beschrijven we onze werkwijze en presenteren we de onderzoeksresultaten (par. 3). Aansluitend trekken we conclusies en doen we aanbevelingen voor vervolgonderzoek (par. 4). Het artikel wordt afgesloten met een korte slotbeschouwing (par. $5)$.

\section{Vraagstelling en begrippenkader}

Onze belangrijkste vraag is: in hoeverre is er wetenschappelijke onderbouwing voor de effecten van supervisie? Daarbij richten we ons vooral op het domein van de gezondheidszorg en de medische opleiding, omdat onderzoek naar reflectie en supervisie juist op dit gebied de afgelopen jaren relatief veel aandacht heeft gekregen. Een aantal begrippen willen we op voorhand definiëren: supervisie, reflecteren en effecten.

\section{Supervisie}

Siegers (2002, p. 31-32) omschrijft supervisie als een didactische methode gericht op het (beter) leren uitvoeren van geprofessionaliseerd dienstverlenend werk, waarin het doelgericht hanteren van de relatie een rol speelt. Leren in supervisie is leren op basis van reflectie. Supervisie richt zich op het ontwikkelen van zelfgestuurd leren bij de supervisant. De supervisant leert in de uitvoering van zijn werk op integratieve wijze en op basis van zelfsturing te functioneren. Op integratieve wijze werk uitvoeren veronderstelt een functioneren vanuit de samenhang tussen denken, voelen en handelen (integratie op het eerste niveau) en vanuit de samenhang tussen persoon, beroep en concrete werksituatie (integratie op het tweede niveau; Siegers, 2002, p. 176).

\section{Reflecteren}

Regouin (1999, p. 98) beschrijft reflecteren als 'terugkijken, bespiegelend overdenken en zoeken naar de betekenis van wat men heeft gezien, ervaren, gedacht of gedaan en daaruit ook lering trekken'. Aukes (2008, p. 109-110) verruimt dit door ook de kwaliteit van het professioneel functioneren en een wetenschappelijke invalshoek als doel van reflectie te onderscheiden: 'Het is ook verkregen inzicht inzetten voor het onderhouden en verbeteren van de kwaliteit van het eigen functioneren en van de medische praktijk. Daarnaast wordt van dokters 
verwacht dat zij wetenschappelijk kunnen reflecteren. (...) Reflectie is echter geen doel op zich, maar een onontbeerlijk ingrediënt van professioneel medisch handelen. (...) Evenwichtig functioneren van dokters is in de eerste plaats van belang voor de kwaliteit van de patiëntenzorg, maar ook voor het permanent ontwikkelen van vakbekwaamheid, interprofessionele samenwerking en niet in de laatste plaats voor hun eigen welbevinden.'

\section{Effecten}

In evaluatieonderzoek worden twee betekenissen van effecten of werkzaamheid onderscheiden: enerzijds werkzaamheid in de zin van bewezen werkzaamheid ('efficacy') en anderzijds werkzaamheid in de zin van doeltreffendheid en effectiviteit bij toepassing op grote schaal ('effectiveness'; Last, 1988, p. 41). Een bewezen werkzame methode hoeft nog geen effectieve methode te zijn, bijvoorbeeld omdat deze slechts werkzaam is op de korte termijn of omdat de werkzaamheid afhankelijk is van de context. Wij vatten voor het doel van dit artikel effecten op in brede zin: reacties, ervaringen, kennis, inzichten, vaardigheden en effecten op professioneel en persoonlijk functioneren op de kortere en langere termijn (Kirkpatrick, 1987).

\section{Methode en resultaten}

In deze studie hebben we een ruime zoektocht in de literatuur uitgevoerd met trefwoorden als 'effect(en)', 'efficacy', 'effectiveness', 'impact', 'reflectie', 'reflection', 'supervisie', 'supervision' en 'reflective practices'. Deze zoektocht beperkten we tot PubMed (zie www.pubmed.com), gerelateerde artikelen en ons bekende Nederlandstalige, Engelse en Duitse literatuur en proefschriften. We streefden daarbij niet naar een verantwoorde begripsafbakening of naar volledigheid, omdat de in de literatuur gebruikte begrippen slecht zijn omschreven en geoperationaliseerd en omdat er weinig evaluatieonderzoek op dit gebied is uitgevoerd. Het ging dus meer om een screening van de literatuur op aanwijzingen voor effecten dan om een toetsing om de feitelijke effectiviteit in te schatten.

\section{Selectie van effecten}

Om de vraag naar effecten te kunnen beantwoorden, is het zinvol vast te stellen ten aanzien van welke uitkomsten of eindpunten effecten kunnen worden verwacht. Uitgaande van de bovenstaande omschrijving van supervisie kunnen we effecten verwachten op het gebied van:

- blijvend reflecteren, doorgaand leren;

- beter persoonlijk functioneren (integratie van denken, voelen, handelen);

- beter professioneel functioneren (integratie van persoon, beroep en werksituatie) en beter vakinhoudelijk handelen.

Het is belangrijk te weten in hoeverre ontwikkelde vaardigheden stabiele vaardigheden vormen die over een langere periode blijven bestaan (duurzaamheid of 'sustainability') en of ze al dan niet casus- of domeingebonden zijn (generaliseerbaarheid).

\section{Blijvend reflecteren, doorgaand leren}

In hoeverre is er wetenschappelijke onderbouwing voor de effecten van supervisie? Er zijn aanwijzingen dat reflectie-ervaringen en -onderwijs het leren in de praktijk bevordert, intensiveert en/of versnelt. In een pilot gaven twaalf als 'klinisch goed' beoordeelde huisartsen in open interviews aan dat zij reflectie over ervaringen met patiënten en collega's als een belangrijke stimulans voor hun leren in de praktijk onderkenden (Sargeant e.a., 2009). De resultaten van de onderwijsprogramma's van Boenink (2005) en Aukes (2008) in de preklinische fase laten zien dat ondersteund ervaringsleren effect heeft, maar dat casusgebondenheid een rol speelt. Reflectieve vaardigheden lijken meetbaar en leerbaar, maar komen ook vanzelf op gang. Reflectieonderwijs kan dit proces versnellen.

We hebben in de literatuur geen studies gevonden die de genoemde effecten over een langere periode hebben getracht te meten. Wel beschreven Mamede en Schmidt (2005), in een vragenlijststudie onder 202 Braziliaanse artsen, dat artsen die reeds langer praktiseerden en artsen die praktiseerden in settings waar de wetenschappelijke basis van de medische zorg niet werd gestimuleerd, minder reflectieve activiteiten ondernamen dan artsen die recent waren opgeleid en die in een meer academisch gefundeerde setting praktiseerden.

\section{Beter persoonlijk functioneren}

Er zijn zowel in Nederland als daarbuiten ruime aanwijzingen dat studenten en (huis)artsen (in opleiding) reflectie en supervisie als werkzaam en effectief ervaren (Grant, 2007; Mann, 2009). Zo noemen huisartsen in opleiding experimenteren met eigen gedrag en leren omgaan met conflicten belangrijke effecten van het volgen van supervisie in hun opleiding (Brenninkmeijer, 1986; Brenninkmeijer, 1999). Ze worden zich meer bewust of problemen binnen of buiten henzelf liggen en gaan duidelijker grenzen stellen (Locher, 2004). Langer gevestigde huisartsen gaven in een exploratief onderzoek na het volgen van een supervisie aan beter irritaties, boosheid, onzekerheid en machteloosheid te kunnen uiten, conflicten beter te kunnen hanteren, beter om te kunnen gaan met eisende patiënten en werkdruk, en beter de eigen grenzen te kunnen bewaken (Brenninkmeijer, 2005). Ten slotte zijn recentelijk positieve ervaringen gemeld door oudere huisartsen die participeerden in een supervisietraject voor oudere huisartsen die zich niet meer thuis voelden in het vak en zich ergerden aan de 
dagelijkse papierwinkel en de diensten (Visser, 2008).

Empirisch onderzoek naar de effecten van groepssupervisie in een ziekenhuis (voornamelijk onder verpleegkundigen) toonde aan dat de deelnemers na afloop van het supervisietraject de samenwerking met artsen en de arbeidsorganisatie als minder belastend ervaarden (Wittich \& Dieterle, 2009). Ook kwam uit dit onderzoek naar voren dat $80 \%$ van de deelnemers vond dat de supervisie zeer veel $(40 \%)$ of enigszins $(40 \%)$ had bijgedragen aan het zelfinzicht.

Vergelijkbare resultaten zijn recentelijk gerapporteerd als resultaat van intervisiegesprekken met assistenten in opleiding tot specialist interne geneeskunde (aio's) in de vorm van incidentenbesprekingen in de intramurale setting (Festen, 2008; Rietmeijer, 2008). De besprekingen blijken een stimulans voor meer openheid, onderling vertrouwen en afname van onzekerheid onder jongere aio's doordat ze ervaren dat andere assistenten en ook geoefende specialisten dezelfde problemen en emoties ondervinden en dat die bespreekbaar zijn. Het met elkaar bespreken van moeilijke situaties stimuleert het dragen van de eigen verantwoordelijkheid.

Een beperking van vrijwel al deze evaluatiestudies is dat ze zijn uitgevoerd bij artsen (in opleiding) die zelf voor een reflectietraining of supervisie hebben gekozen, dat er geen controlegroep is of dat bijvoorbeeld de formulering van de gebruikte vragenlijsten al een vertekening ('bias') in de gewenste richting induceert (Kuyvenhoven, 2009).

Ook bij andere professies in de zorg zijn vergelijkbare ervaringen opgetekend. In een vragenlijstonderzoek in de ggz geeft het merendeel van de respondenten aan supervisie een goede manier van leren te vinden: de negatieve spiraal is doorbroken, waardoor er weer positief en functioneel gewerkt kan worden. Supervisie levert een belangrijke bijdrage aan het vergroten van het inzicht in het eigen functioneren. De integratie van denken, voelen en handelen heeft aandacht gehad (Vrieze, 2006).

Kruiswijk (2004) destilleert effecten van supervisie uit een studie waarbij de responsieve evaluatietechniek werd toegepast op twaalf opleidingssupervisies (hbo verpleegkunde). Overkoepelend resultaat lijkt te zijn het ontwikkelen van identiteit in het verpleegkundig beroep en het ontwikkelen van eigenheid in de beroepsuitoefening (eigenwijs, eigenaardig en eigenhandig denken, voelen, handelen).

\section{Beter professioneel functioneren en vakinhoudelijk handelen}

Boenink (2004) laat in een studie onder vierdejaars medische studenten zien dat beter kunnen reflecteren na afloop van een trainingsprogramma samenhangt met betere kennis van professionele opvattingen bij dilemma's en dat een hogere overall score voor reflectie samenhing met meer aandacht geven aan het patiëntenperspectief, meer melden van medische overwegingen en meer aandacht voor persoonlijke gevoelens en normen. Windish (2005) constateerde dat studenten die deelnemen aan een gestructureerd feedback- en

reflectieonderwijsprogramma beter contact konden leggen met simulatiepatiënten en dat zij meer psychosociale problemen en meer onderwerpen uit de medische historie in hun probleemlijst meldden. Andere studies ondersteunen deze samenhang tussen reflectieve vaardigheden en de kwaliteit van vakinhoudelijk handelen, zoals diagnostische accuratesse bij meer complexe problemen bij reeds gevestigde artsen, en bij het aanleren van medisch technische vaardigheden (Kuyvenhoven, 2009).

In het eerder genoemde onderzoek van Wittich en Dieterle (2009) kwam naar voren dat 88 procent van de deelnemers ten minste enigszins en 61 procent veel of zeer veel had geprofiteerd van de supervisie. Deze inschatting was onafhankelijk van leeftijd, geslacht, functie en afdelingen. De effectiviteit van de supervisie werd in dit onderzoek nog uitgesplitst naar samenwerking in het verpleegkundig team (zeer veel nut: $42 \%$ ), samenwerking met artsen (22\%), arbeidsorganisatie (23\%) en patiëntenzorg (48\%).

\section{Vervolgonderzoek}

Onderzoek naar de effecten van supervisie en/of reflectie is schaars. De meeste publicaties die we vonden komen uit de medische wereld en de zorg. We trekken de volgende conclusies uit dit onderzoek.

- Er zijn aanwijzingen dat reflectie-ervaringen en -onderwijs het leren in de praktijk bevordert, intensiveert en/of versnelt. In de literatuur zijn echter geen studies beschreven die effecten van reflectietraining of supervisie op langere termijn hebben getracht vast te stellen.

- Er zijn aanwijzingen dat supervisie de ervaren arbeidsbelasting verlaagt en leidt tot een groter zelfinzicht en toename van de persoonlijke effectiviteit (zoals grenzen stellen, omgaan met conflicten, uiten van emoties).

- Er zijn aanwijzingen dat een grotere vaardigheid in reflecteren samenhangt met sterkere vaardigheden op andere aspecten van professioneel gedrag, zoals het maken van een meer gedegen afweging bij morele dilemma's, meer kennis van professioneel correct gedrag en meer aandacht voor medisch inhoudelijke en patiëntgebonden overwegingen bij medische beslissingen. Er zijn geen aanwijzingen voor generaliseerbaarheid van aangeleerde reflectieactiviteiten naar andere gebieden.

- Kunnen reflecteren hangt mogelijk samen met betere communicatieve vaardigheden, beter contact kunnen leggen met patiënten, beter gebruik maken van medische gegevens in een probleemlijst, een betere diagnostische accuratesse en het beter aanleren van nieuwe medisch-technische vaardigheden. Er zijn geen aanwijzingen voor generaliseerbaarheid buiten het gebied waarop de reflectieactiviteiten plaatsvinden.

\section{Begrippenkader}

We denken redelijk volledig te zijn waar het Nederlands empirisch onderzoek naar supervisie betreft. Het opsporen van internationale publicaties naar de effecten en effectiviteit van supervisie is moeilijker vanwege de 
relatief diffuse begripsomschrijving van begrippen als reflectie, 'reflection', 'reflective practice', supervisie en 'supervision'. Een internationaal gedeeld perspectief op deze begrippen ontbreekt. Verder lijkt het ons zinnig in de toekomst vergelijkende analyses te kunnen maken met resultaten in andere sectoren, zoals onderwijs, zorg en bedrijfsmanagement.

\section{Niveau van effecten}

De effecten van supervisie zijn veelal gedefinieerd op het niveau van reacties, ervaringen en inzichten van supervisanten. Er is weinig tot geen onderzoek bekend over de effecten van supervisie op het gedrag van de supervisanten of de resultaten daarvan voor hun professionele omgeving (cliënten, collega's, organisatie). Onderzoek hiernaar kan een bijdrage leveren aan het versterken van de positie van supervisie in de markt.

Lankamp en Santman (2009) doen in hun artikel een aanzet tot het zichtbaar maken van het rendement van coaching. Deze aanzet is wellicht ook bruikbaar voor supervisie. Binnen de Nederlandse huisartsopleiding worden reflectieve vaardigheden binnen het taakgebied 'professionaliteit' longitudinaal en gestandaardiseerd beoordeeld, zodat de samenhang met de verschillende fasen van de opleiding zichtbaar kan worden gemaakt (Van Katwijk, 2005; Kuyvenhoven, 2009).

Bennink (2001) verkende de mogelijkheden van 'goal attainment scaling' (GAS) voor het evalueren van de resultaten van begeleidingsprocessen. Op grond van zijn onderzoek concludeert Bennink dat beter met GAS gewerkt kan worden naarmate de competentie beter kan worden omschreven in gedragsmatige termen. Binnen supervisie- of intervisietrajecten kan GAS een hulpmiddel zijn om werkplek- en vaardigheidsgerelateerde leerdoelen te formuleren en evalueren.

\section{Onderwerpen voor vervolgonderzoek}

De gezondheidszorg biedt relevante en vruchtbare mogelijkheden voor het uitvoeren van evaluatieonderzoek. Professioneel omgaan met patiënten en collega's stelt hoge eisen aan het kennen van en kunnen hanteren van de eigen persoon in deze relaties. Er is altijd de verleiding toe te geven aan druk van patiënten en collega's en daarmee de eigen professionele grenzen te overschrijden (Alting von Geusau, 1991; Balint, 1957; Van de Voort, 1993). Reflecteren biedt een mogelijkheid om inzicht in deze samenhang te krijgen en de spanningen in de relatie tussen deze verschillende domeinen te reduceren (Argyris, 1974).

Tegenwoordig wordt het CanMEDS-model steeds meer wordt omarmd; de algemene competenties van de medisch specialist, zoals medisch handelen, communicatie, samenwerking, kennis en wetenschap, maatschappelijk handelen, organisatie en professionaliteit (Frank, 1996; Kaderbesluit CCMS, 2004; Van Katwijk, 2005). Daardoor was er in het afgelopen decennium een sterke toename van reflectieonderwijs in de initiële en medische vervolgopleidingen te constateren. Dit heeft tot gevolg dat er een systematische evaluatie van werkwijze en effecten geïndiceerd is voor de medische opleiding als zelflerende institutie, en dat deze vruchtbaar kan zijn voor de verdere theorievorming. Daarbij is het belangrijk parallellen te onderzoeken tussen de resultaten bij andere professies, zoals verpleegkundigen, leidinggevenden, docenten en professioneel begeleiders om zo meer zicht te krijgen op de generaliseerbaarheid van resultaten.

Er zijn aanwijzingen dat supervisie leidt tot een toename van zelfinzicht en persoonlijke effectiviteit. Wij vragen ons af in hoeverre een verbeterd persoonlijk functioneren ook een bijdrage levert aan het voorkómen van burn-out en intrapsychische en gedragsproblemen. Bekend is dat werkgerelateerde stress, lage werksatisfactie en lifeevents een risicofactor vormen voor burn-out bij artsen, assistenten, maar ook studenten (Dyrbye, 2006; Van der Heijden, 2006; Prins, 2007b, 2008; Soler, 2008; Visser, 2003). De relatie met verpleegkundigen en supervisoren/werkbegeleider en het al dan niet ontvangen van emotionele steun van opleiders, speelt in deze samenhang mogelijk een rol (Prins, 2008; Dyrbye, 2008).

Het lijkt plausibel te veronderstellen dat het kunnen stellen van persoonlijke grenzen, kunnen omgaan met conflicten en kunnen omgaan met emoties in goede werkomstandigheden intrapsychische problemen (zoals emotionele uitputting en burn-out) kan voorkomen. Om dit te bereiken lijkt een gedegen reflectietraining of supervisie in de opleiding een vruchtbare strategie, maar hiervoor zijn geen empirische aanwijzingen gevonden. Dergelijke samenhangen zijn echter moeilijk te onderzoeken doordat ook andere factoren zoals werkomstandigheden en life-events een grote rol zullen spelen in het ontstaan van dergelijke problemen op de langere duur.

Onderzoek naar effecten van supervisie kan ertoe leiden dat men zich vooral richt op het legitimeren van supervisie. De jarenlange onderzoekstraditie op het gebied van psychotherapie (o.a. Schagen, 1993) heeft aangetoond dat dit een 'mission impossible' is. Onderzoekresultaten zijn soms voor verschillende uitleg vatbaar en kunnen elkaar tegenspreken. Ten behoeve van verdere kennisontwikkeling is vooral ook de vraag naar hoe de effecten tot stand komen zinvol. In dat verband is de vraag naar helpende interventies relevant: wat zijn effectieve interventies van supervisoren, wanneer in het traject, bij welke leer- en werkvragen en van welke supervisanten?

\section{Relatie met aanverwante onderzoeksgebieden}

Kennisontwikkeling over supervisie kan gevoed worden door supervisieonderzoek te koppelen aan begrippen die ingebed zijn in wetenschappelijk onderbouwde theorieën. Bakens (2001) introduceert bijvoorbeeld het begrip selfefficacy (geloof in eigen kunnen) als belangrijke effectmaat van supervisie. Dit begrip heeft een uitgebreide wetenschappelijke basis en is een kernbegrip uit de sociale leertheorie van Bandura (1977). Geloof in eigen kunnen is de belangrijkste voorspeller van gedrag en wordt voornamelijk gevoed door ervaring (oefenen, succes en faalervaringen), voorbeeldgedrag en feedback. Er bestaat volgens Bakens een duidelijke relatie tussen de belangrijkste uitgangspunten van supervisie (zie boven) en self-efficacy. Op het moment dat we door middel van onderzoek meer inzicht krijgen in de relatie tussen supervisie en self-efficacy, ontsluiten we nieuwe mogelijkheden 
voor kennisontwikkeling over de rol van supervisie bij gedragsverandering.

Op de Dag van de Coach 2009 (thema: 'Investeren in kennis') sprak Ben Tiggelaar over 'evidence inspired' werken. Hij pleit voor leren, in tegenstelling tot legitimeren, als basismotivatie voor onderzoek en drukt de toehoorder op het hart: laat je niet intimideren maar inspireren door wetenschappelijk onderzoek. Hierbij is wel voorzichtigheid geboden. Zo waarschuwt Hausinger (2009) voor het vergelijken van supervisieonderzoek met therapieonderzoek, vanwege de grote verschillen tussen beide begeleidingsvormen wat betreft condities, doelen en werkwijzen. Kennis nemen van diverse vormen van psychotherapieonderzoek ziet zij echter als een mogelijk waardevolle ondersteuning en een oriëntatiepunt voor de verdere ontwikkeling van supervisieonderzoek (bijvoorbeeld wat betreft de gehanteerde onderzoeksmethodiek).

\section{Tot besluit}

Onderzoek naar supervisie is een uiterst veeleisende aangelegenheid die vraagt om samenwerking tussen verschillende onderzoeksdisciplines, explicitering van begrippen, vraagstellingen en processen, evenals een kritisch en complex onderzoekbegrip (Hausinger, 2009, p. 242). Het is ondoenlijk om in een grootschalig experimentele opzet de effectiviteit van supervisie op de langere termijn te onderzoeken. Allereerst onderzoektechnisch, aangezien randomisering (elke proefpersoon heeft een van tevoren vastgestelde kans om voor de experimentele groep geselecteerd te worden) moeilijk te realiseren is en doordat de aantallen groot moeten zijn om over een periode van vijf tot tien jaar daadwerkelijk effecten te meten.

Het lijkt niet zinvol te streven naar een grootschalige studie om de effectiviteit van supervisie te meten. Effectiever is te kiezen voor kleinschalige onderzoeken met combinaties van diverse onderzoeksmethoden (zoals handelingsonderzoek, procesonderzoek, gevalsstudie, combinatie van kwalitatief en kwantitatief onderzoek). Of zoals Norman (2008) met betrekking tot onderwijskundig evaluatieonderzoek heeft gesuggereerd: 'The goal is a research program, not a study. Each study is viewed as one data point in a much larger array. Successive studies devolve from a growing and dynamic theory, end each, in turn, informs the theory.'

* Mieke Voogd is eigenaar van Coach ${ }^{2}$, praktijk voor supervisie, coaching en organisatieontwikkeling te Eelde, en voorzitter van de Commissie Kennis en Onderzoek van de LVSC. E-mail: mieke@coachkwadraat.nl.

Marijke Kuyvenhoven is universitair hoofddocent bij de Afdeling Huisartsgeneeskunde van de Divisie Julius Centrum voor Gezondheidswetenschappen en Eerstelijnsgeneeskunde van het UMC Utrecht en NHG-supervisor.

\section{Noten}

1. Associatie van nationale supervisie organisaties in Europa.

\section{Bibliografie}

1. Alting von Geusau, W., \& Runia, E. (1999). De prijs van het aardig zijn. Supervisie als nascholingsmethode. Utrecht: NHG.

2. Argyris, D., \& Schon, D. (1974). Theory into practice: Increasing professional effectiveness. San Francisco: Jossey Bass.

3. Aukes, L.C. (2008). Personal reflection in medical education. (Dissertatie.) Groningen: Rijksuniversiteit Groningen.

4. Bakens, P. (2001). Self-efficacy en supervisie. Supervisie in Opleiding en Beroep, 18 (2), 83-95.

5. Balint, M. (1957). The doctor, his patient and the illness. Londen: Pitman.

6. Bandura, A. (1977). Self-efficacy: Towards a unifying theory of behavioural change. Psychological Review 84 , 191-215.

7. Bennink, H. (2001). Goal attainment scaling en evaluatie van professionele begeleiding. Supervisie in Opleiding en Beroep, 18 (3), 154-170.

8. Boenink, A.D., Oderwald, A.K., Jonge, P. de, Tilburg, W. van, \& Smal, K. (2004). Assessing student reflection in medical practice. The development of an observer-rated instrument: Reliability, validity and initial experiences. Medical Education, 38, 368-377.

9. Bouman, G., \& Bergen, T. (2004). Hoe krachtig is supervisie als leeromgeving? Supervisie en Coaching, 21, 119-134.

10. Brenninkmeijer, W., Grol, R., \& Lieshout, A.M. van (1986). Evaluatie van supervisie en persoonsgerichte training. Huisarts en Wetenschap, 29, 319-321.

11. Brenninkmeijer, W.J.M, Mokkink, H.G.A., Schuling, J., Voorn, Th. B., \& Wijdeven, M.H.T. (2005). Leren van eigen werkervaringen. Onderzoek naar de effecten van supervisie aan huisartsen. Medisch Contact, 60, 664667.

12. Brenninkmeijer, W.J.M, Rossum, M.M. van, \& Mokking, H.G.A. (1999). De evaluatie van supervisie voor haio's. Huisarts en Wetenschap, 42, 402-405.

13. Dyrbye, L.N. (2008). Burnout in medical professionals. Prevalence, consequences and prevention. Hoofdlezing congres NVMO, Egmond aan Zee, 13-14 november. Internet: www.nvmo.nl/congres/nvmocongres2008. 
14. Dyrbye, L.N., Thomas, M.R., Huntington, J.L., Lawson, K.L., Novotny, P.J., Sloan, J.A., \& Shanafelt, T.D. (2006). Personal life events and medical student burnout: A multicenter study. Academic Medicine, 81, 374384.

15. Festen, H.P.M., Broek, H.M.L. van den, Deijne, M.W.C. van, Freriks, K., \& Netten, P.M. (2008). Leerzame openheid. De incidentbespreking tijdens de medisch-specialistische opleiding. Medisch Contact, 63, 11761179.

16. Frank, J.R., Jabbour, M., \& Tugwell, P. (1996). Skills for the new millennium. Report of the societal needs working group, CanMEDS 2000 project. Annals of the Royal College of Physicians and Surgeons of Canada, 29, 206-216.

17. Grant, A.J., Vermunt, J.D., Kinnersley, P., \& Houston, H. (2007). Exploring students' perceptions on the use of significant event analysis, as part of a portfolio assessment process in general practice, as a tool for learning how to use reflection in learning. BMC Medical Education, 7, 5.

18. Hausinger, B. (2009). Ausblicke. In R. Haubl \& B. Hausinger (red.), Supervisionsforschung: Einblicke und Ausblicke (p. 242). Göttingen: Vandenhoeck \& Rupecht.

19. Heijden, F.M.M.A. van der, Dillingh, G.S., Sprangers, F., Bakker, A.B., \& Prins, J.T. (2006) Toegewijd, maar oververmoeid. Medisch Contact, 61, 1792-1795.

20. Katwijk van, P. (2005). De beoordeling van opleidingssupervisie voor huisartsen. Supervisie en Coaching, 22, 58-72.

21. Kirkpatrick, D.L. (1987). Evaluation of training. In: R.L. Craig (Ed.), Training en development handbook: $A$ guide to human resource development (p. 309-319). New York: McGraw-Hill.

22. Kruijswijk Jansen, J. (2004). Speuren naar de effecten van supervisie. Supervisie en Coaching, 21, 135-149.

23. Kuyvenhoven, M.M. (2009). Reflectie en supervisie in de medische opleiding. Ervaringen en effecten. (Werkstuk in het kader van NHG-Kaderopleiding Supervisie.)

24. Lankamp, W., \& Santman, H. (2009). Inzicht in het rendement van coaching. Tijdschrift voor Coaching, 6, 7173.

25. Last, J.M. (1988). A dictionary of epidemiology. New York/Oxford/Toronto: Oxford University Press.

26. Locher, G., \& Blankenstein, A.H. (2004). Wat doet supervisieonderwijs bij huisartsen in opleiding? Resultaten van een onderzoek naar effectbeleving onder HAIO's aan de huisartsopleiding van VUMC. Tijdschrift voor Medisch Onderwijs, 23, 153-160.

27. Mamede, S., \& Schmidt, H. (2005). Correlates of reflective practice in medicine. Advances in Health Sciences Education: Theory and Practice, 10, 327-337.

28. Mann, K., Gordon, J., \& Macleod, A. (2009). Reflection and reflective practice in health professions education: A systematic review. Advances in Health Sciences Education: Theory and Practice, 14, 595-62.

29. Prins, J.T., Gazendam-Donofrio, S.M., Dillingh, G.S., Wiel, H.B. van de, Heijden, F.M. van der, \& HoekstraWeebers, J.E. (2008). The relationship between reciprocity and burnout in Dutch Medical residents. Medical Education, 42, 721-728.

30. Prins, J.T., Gazendam-Donofrio, S.M., Tubben, B.J., Heijden, F.M.M.A. van der, Wiel H.B.M. van de, \& Hoekstra-Weebers, J.E. (2007b). Burnout in medical residents: A review. Medical Education, 41, 788-800.

31. Prins, J.T., Hoekstra-Weebers, J.E., Wiel, H.B. van de, Gazendam-Donofrio, S.M., Sprangers, F., Jaspers, F.C., Heijden, F.M. van der (2007a). Burnout among Dutch medical residents. International Journal of Behavioral Medicine, 14, 119-125.

32. Regouin, W. (1999). Supervisie. Gids voor supervisanten. Assen: Van Gorcum.

33. Rietmeijer, C.B.T., Soesan, M., Brandjes, D.P.M., \& Mairuhu, R.T.A. (2008). De vergeten competenties. Intervisie voor aio's verbetert communicatie, samenwerking en professionaliteit. Medisch Contact, 63, 16921696.

34. Sargeant, J.M., Mann, K.V., Vleuten, C.P. van der, \& Metsemakers, J.F. (2009). Reflection. A link between receiving and using assessment feedback. Advances in Health Sciences Education: Theory and Practice, 14, 399-410.

35. Schagen, S. (1983). Het effect van psychotherapie, meetbaarheid en resultaten. Deventer: Van Loghum Slaterus.

36. Siegers, F. (2002). Handboek supervisiekunde. Houten: Bohn Stafleu van Loghum.

37. Soler, J.K., Yaman, H., Esteva, M., Dobbs, F., \& Asenova, R.S. (2008). Burnout in European family doctors: The EGPRN study. Family Practice, 25, 245-265.

39. Visser, J. (2008). Welbewust ouder. Senior huisartsen bezinnen zich op nieuwe levensfase. Medisch Contact, 63, 1873-1875.

40. Visser, M.R.M., Smets, E.M.A., Oort, F.J., \& Haes, H.C.J.M. de (2003). Stress, satisfaction and burnout among Dutch medical specialists. Canadian Medical Association Journal, 168, 271-275.

41. Voogd, M.C. (2008). Meten en leren van supervisieresultaten. (Werkstuk opleiding supervisiekunde.) Groningen: HanzeConnect.

42. Voort, H.P.M. van der (1993). Supervisie bij uitstek geschikt voor huisartsen. Huisarts en Wetenschap, 36, 252-254. 
43. Vrieze, T. (2006). Supervisie in de GGZ Groningen. (Werkstuk opleiding supervisiekunde.) Groningen: HanzeConnect.

44. Windish, D.M., Price, E.G., Clever, S.L., Magaziner, J.L., \& Thomas, P.A. (2005). Teaching medical students the important connection between communication and clinical reasoning. Journal of General Internal Medicine, 20, 1108-1113.

45. Wittich, A., \& Dieterle, W.E. (2009). Empirische Supervisionsforschung. Ein Beitrag aus dem Krankenhaus. In R. Haubl \& B. Hausinger (red.), Supervisionsforschung: Einblicke und Ausblicke (pp. 12-28). Göttingen: Vandenhoeck \& Rupecht.

(C) 2009, Bohn Stafleu van Loghum, Houten 